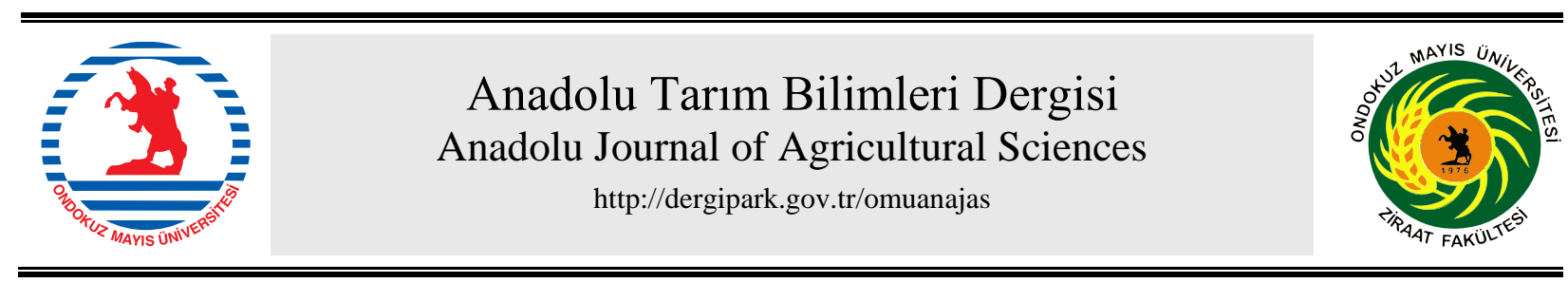

Araştırma/Research

Anadolu Tarım Bilim. Derg./Anadolu J Agr Sci, 35 (2020)

ISSN: 1308-8750 (Print) 1308-8769 (Online)

doi: 10.7161/omuanajas.777064

\title{
Orta Anadolu Bölgesi Aridisol Topraklarının Özellikleri ve Arazi Değerlendirmesi
}

\author{
๑Mert Dedeoğlu ${ }^{\mathrm{a}^{*}}$, ๑Hasan Hüseyin Özaytekin ${ }^{\mathrm{b}}$, @Levent Başayiğit ${ }^{\mathrm{c}}$ \\ a Selçuk Üniversitesi, Ziraat Fakültesi, Toprak Bilimi ve Bitki Besleme Bölümü, Konya, Türkiye \\ ${ }^{\mathrm{b}}$ Karamanoğlu Mehmetbey Üniversitesi, Teknik Bilimler Meslek Yüksekokulu, Organik Tarım Programı, Karaman, Türkiye \\ c Isparta Uygulamalı Bilimler Üniversitesi, Ziraat Fakültesi, Toprak Bilimi ve Bitki Besleme Bölümü, Isparta, Türkiye
}

*Sorumlu yazar/corresponding author: mdedeoglu@selcuk.edu.tr

Geliş/Received 05/08/2020 Kabul/Accepted 24/08/2020

\begin{abstract}
ÖZET
Ülkemizin Güney Doğu Anadolu Bölgesinde geniş yayılım gösteren ve kurak bölge toprakları olarak da isimlendirilen Aridisoller, toprak özellikleri ile uzun yıllar ortalama iklim verilerinin Newhall modeline göre değerlendirilmesi sonucu Orta Anadolu Bölgesinde dağılım gösteren toprak sınıfları arasında önemli bir yer kaplamaktadır. Bu çalışmada, Konya ovasında yaklaşık 5140 ha büyüklüğündeki Beşgözler K.O.P. alanı detaylı toprak etüd çalışması sonucu tanımlanan Aridisol ordosuna ait toprakların genel özellikleri yer almaktadır. Bu toprakların FAO Toprak Verimlilik İndeksine göre parametrik olarak arazi değerlendirilmesi yapılmış ve CBS ortamında haritalanmıştır. Çalışma sonucunda 1950 ha (\% 38) alan 2 farklı seride Toprak Taksonomisine göre Aridisol ordosunun Typic Haplocalcids ve Typic Haplocambids alt toprak grubunda sınıflandırılmıştır. Bölge Aridisollerinin FAO Toprak Verimlilik İndeksine göre arazi değerlendirmesi sonucu tarımsal kullanıma uygunluk II. sınıf (S2) iyi nitelikli tarım arazileri \% 60.50, III. sınıf (S3) orta nitelikli tarım arazileri \% 39.32, IV. sınıf (S4) zayıf nitelikli tarım arazileri \% 0.18 oranında alansal dağılım gösterdiği belirlenmiştir. Bu alanların mutlak tarım arazisi niteliğinde olduğu, kuru şartlarda karlılık sırası ile buğday veya arpa, sulu şartlarda ise uygunluk sırası ile şeker pancarı, ayçiçeği, mısır veya fasulye yetiştiriciliğinin yapılabileceği önerilmiştir.
\end{abstract}

\section{Properties and land evaluation of the aridisol soils in central anatolian}

\section{ABSTRACT}

Aridisols, which are widely distributed in the South East Anatolia Region in TURKEY and are also called as arid region soils, it also occupies an important place among the soil classes in the Central Anatolian Region, when soil characteristics and long term average climate data are evaluated according to Newhall model. In this study, the general characteristics of the territories belonging to the Aridisol ordinance, which is defined as the result of a detailed soil survey study on the area of Beşgözler in the size of 5140 hectares in the Konya plain. The land was evaluated parametrically according to the FAO Soil Productivity Index and mapped in the GIS environment. In the results of study, 1950 hectares are identified in Aridisol order from 2 different series according to soil taxonomies and the soil was classified as Typic Haplocalcids in the subsoil group. According to the results of suitability classifications with FAO Soil Productivity Index was determined that the Aridisols of the region have been distributed as $60.50 \%$ for class II (S2) good quality, 39.32\% for class III (S3) medium quality and $0.18 \%$ for class IV (S4) poor agricultural land. Also, the results it was concluded that these areas are the absolute agricultural land, in addition, in these areas for wheat or barley with profitability under dry conditions, furthermore, the areas are suitable for sugar beet, sunflower, corn or bean under irrigation conditions.
Anahtar Sözcükler:

Konya ovası

Kurak ekosistem

Newhall

Toprak verimlilik

indeksi
Keywords:

Arid ecosystem

Konya basin

Newhall

Soil productivity index

(C) OMU ANAJAS 2020 


\section{Giriş}

Ülkemizde ve Dünyada değişen iklim, su kaynaklarının azalması ve hızla artan insan nüfusu gibi küresel düzeyde birçok problem potansiyel tarım alanları üzerindeki baskıyı artırmaktadır. Tüm bu baskıların yanında tarım ürünlerine olan ihtiyaç büyümekte ve talebin karșılanması için harcanan ekonominin hem üretici hem de tüketici bazında kontrolsüz olarak yükselmesine neden olmaktadır (Blum, 1993; Dengiz ve Kurşun, 2018). Ancak üretim ortamı olan topraklarımızın miktarında bir artış olmadığı gibi bilimsel esaslara dayanmadan ve maksat dışı kullanımlarla mevcut tarım arazilerinin miktarı yıllar içinde bozulmakta, yanlış planlama ve yanlış arazi kullanımı sonucu verim ile birlikte sürdürülebilirlik de azalmaktadır (Karlen ve ark., 2001). Sürdürülebilir toprak verimliliği uygun yönetim sistemleri altında toprakların niteliklerini bozmadan bitki üretme kapasitesidir (Pierce ve ark., 1983; Mueller ve ark., 2010). Bu kapasiteyi, ekolojiyi bozmadan optimum seviyeye çıkarmak için toprakların yakından tanınması ve bu tanımlamaya uygun işletilmesi gerekmektedir (FAO, 1976; Şenol, 1983). Bu amaçla başvurulan en önemli kaynak toprak haritalarıdır (Rogowski ve Wolf, 1994; Dengiz ve Sarıoğlu, 2011). Toprak etüd ve haritalama çalışmaları sonucu üretilen toprak haritaları ile topraklar sahip oldukları özelliklere göre sinıflandırılmakta ve tarımsal planlamalarda, çevresel etkilerin modellenmesinde, değişik mühendislik dallarında ve doğal kaynakların planlanması ve korunması çalışmalarında kullanılmaktadır (Dengiz ve Sarığlu, 2011). Toprak sınıflaması amaciyla kullanılan yaygın ve kapsamlı sistem Toprak Taksonomisi'dir (Soil Survey Staff, 1999). Toprak taksonomisi, toprak yapan işlem ve faktörlerin yanında sıcaklık ve nem rejimlerinin sinıflandırıcı özellik olarak kullanıldığg toprağın ölçülebilen ve gözlenebilen özelliklerini esas almaktadır (Başayiğit ve Dinç, 2005). Nitekim toprak nem ve sicaklık rejimleri farklı kategoriler ve derecelerde sınıflamayı etkileyen önemli bir faktördür. Örneğin; Aridisollerin sinıflandırılmasında Aridic toprak nem rejimi ordo seviyesinde sinıflandırma kistası olarak belirtilmektedir (Soil Survey Staff, 1999). Ülkemizde Aridisoller, Güney Doğu Anadolu Bölgesinde geniş bir yayılım göstermekte ve kurak bölge toprakları olarak adlandırılmaktadır (Çakmaklı, 2008). Ancak günümüzde toprak sinıflamasında önemli ve değişmekte olan iklim parametreleri de dikkate alındığında Aridisoller, Orta Anadolu Bölgesinde yer alan toprak sinıfları arasında da önemli bir yer kaplamaktadır (Dengiz, 2007; Tunçay, 2018). Tarımsal açıdan toprak sınıflama ve haritalama çalışmalarında ulaşılmak istenilen asıl hedef ise uygun arazi kullanım planlamasıdır (FAO, 1976; Randolph, 2004). Arazilerin doğal niteliklerinin belirlenmesi ve buna göre ayrımlarının yapılması ve sınıflandırılması onların hangi amaca yönelik olarak kullanılması gerektiğini belirleyen temel faktördür. $\mathrm{Bu}$ nedenle toprakların hangi kullanım türlerine uygun olduklarının değerlendirilmesi ve herhangi bir kullanım altında tavrının tahmin edilmesi modern tarım için bir zorunluluk olmaktadır (Mohit ve Ali, 2006). Arazilerin farklı kullanımlara uygunluğunun belirlenmesi için de arazi değerlendirme çalışmalarının yapılmas1 gerekmektedir (Smyth ve Dumanski, 1993; Verheye, 2009). Arazi değerlendirme, farklı kullanım tipleri altında bir arazinin işlevselliğinin, yeteneklerinin ve üretkenliğinin değerlendirilmesidir (FAO, 1976). Bu nedenle güncel ve güvenilirliği ispatlanmış, günümüz CBS teknolojileri ile uyumlu ve dinamik arazi değerlendirme modelleri ile ülkemiz arazilerinin kullanım planlaması çalışmaları önemli bir gerekliliktir. Tüm bu gerekliliklerin yanında özellikle Aridik bölgelerin sulamaya açılacak alanlarında; uygun toprak ve su koruma tekniklerinin seçilmesi ve toprak özelliklerine bağlı olarak, sulama yöntemlerinin planlanmasında o bölgeye ait toprak etüt ve haritalama çalışmalarının yapılması ve bunların yorumlanıp değerlendirilmesine mutlak ihtiyaç duyulmaktadır (Özbek ve Öztaş, 2002).

$\mathrm{Bu}$ çalışma ile yaklaşık 3 milyon ha tarım arazisi varlı̆̆ıyla ülkemizin önemli tarımsal üretimini karşılayan, aynı zamanda Türkiye'nin en fazla su sıkıntısı çeken Konya Ovası Projesi (K.O.P.) bölgesine ait Sarayönü - Beşgözler proje alanında yürütülen detaylı toprak etüd çalışması sonucu tanımlanan Aridisol ordosuna ait toprakların genel özellikleri belirlenmiş ve FAO Toprak Verimlilik İndeksine göre parametrik olarak arazi değerlendirilmesi yapılarak CBS ortamında haritalanmıştır.

\section{Materyal ve Yöntem}

\section{1 Çalışma alanı jeolojisi ve fizyoğrafyası}

Çalı̧̧ma yaklaşık 5140 ha büyüklüğünde K.O.P. Beşgözler proje alanı topraklarında yürütülmüştür. Çalışma alanı, 38 $38^{\circ} 1^{\prime}-38^{\circ} 16^{\prime}$ Kuzey enlemi ile $32^{\circ} 16^{\prime}$ - 32 ${ }^{\circ} 19^{\prime}$ Doğu boylamı arasında yer almaktadır (Şekil 1). Çalışma sahasında ağılıklı olarak buğday, fasulye, mısır ve şeker pancarı yetiştirilmektedir. Sarayönü ovası içerisinde kalan sahada, Paleozoik'ten Kuaterner'e kadar geçen süre içerisinde oluşmuş formasyonlar bulunmaktadır. Bunlar içerisinde en yaygın olanı Miyosen-Pliyosen yaşlı karasal çökeller ve göl kireçtaşları yer almaktadır (MTA, 2009). Çalışma alanının güneyini çevreleyen dağlar Fillit (şist) ve yarı kristalize olmuş kalkerden oluşmaktadır. Orman örtüsü bakımından zayıf olan bu dağlarda meydana gelen erozyon sonucu şistlerin mekanik ayrışması ile oluşan kil erozyon ile ova tabanına yayılmıştır. Bu nedenle toprak altında farklı derinliklerde yaklaşı $30-40 \mathrm{~cm}$ kalınlığında marn-marnoklaker (kis) tabakaları bulunmaktadır. 


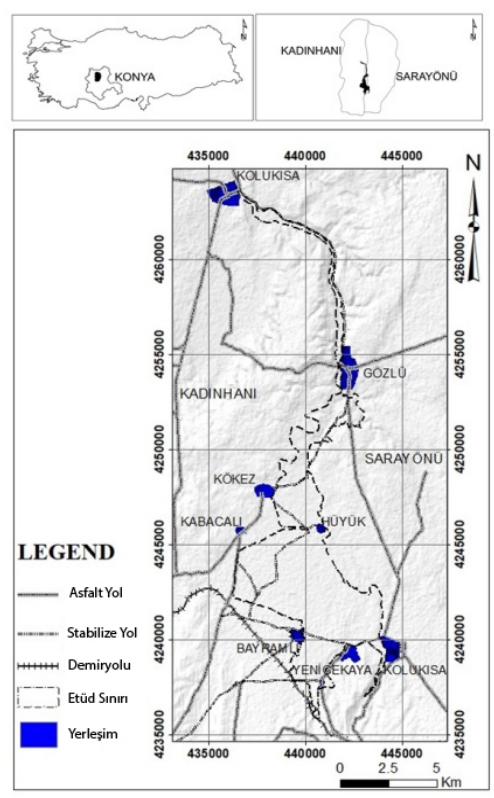

Şekil 1. Çalışma alanı yer buldur haritası

Figure 1. Location map of study area

Araştırma sahası, geçmişte yüksek debi ve genişlikte olan ve kalıntıları günümüzde Beşgöz deresi olarak adlandırılan eski akarsu yatağıdır. Ana fizyolojik ünitelerini yan dere alüvyalleri, eski nehir terasları, taşkın düzlükleri, üst etek araziler ve çamur akıntıları oluşturmaktadır. Genel olarak düz- dalgalı topografyada, düz- düze yakın, hafif eğimde olan Beşgözler Proje Alanı içerisinde birçok düzensiz dere yan dere kolları barındırmaktadır. Sahada yer alan göllerden en önemlisi, Beşgözler Gölü'dür. Çalışma alanının denizden yüksekliği 990 - $1040 \mathrm{~m}$ arasında değişmektedir.

\section{2 İklim}

Proje alanının bulunduğu Sarayönü ilçesi kurak iklim özellikleri göstermektedir. Konya Devlet Meteoroloji Bölge Müdürlüğü'nden alınan verilere göre (Anonim, 2015), bölgede yıllık ortalama yağış miktarı $322.5 \mathrm{~mm}$., yillık sicaklık ortalamas1 $11.5{ }^{\circ} \mathrm{C}$, yıllık buharlaşma ise $1285 \mathrm{~mm}$ 'dir. Etüd alanı ile sınırı bulunan Konuklar Tarım İşletmesinden elde edilen verilere göre $50 \mathrm{~cm}$ toprak derinliğinde yıllık ortalama sıcaklık $13.94^{\circ} \mathrm{C}$, en düşük toprak sıcaklığı $3.32{ }^{\circ} \mathrm{C}$ ile Şubat ayında, en yüksek toprak sıcaklığı $25.03{ }^{\circ} \mathrm{C}$ ile de Ağustos ayında belirlenmiştir. Newhall simülasyon modeline göre (Newhall, 1972; Van Wambeke, 2000), toprak sicaklık rejimi mesic, toprak su bütçesine göre toprak nem rejimi ise aridic olarak belirlenmiştir (Şekil 2).

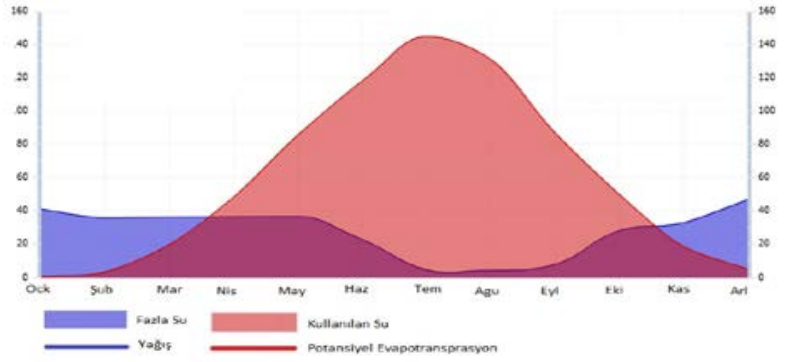

Şekil 2. Çalışma alanı toprakların sıcaklık - nem diyagramı

Figure 2. Soil moisture and temperature regime diagrams of the study area's soil

Benzer şekilde Kapur ve ark., (2017)'e göre, Konya ilinin Newhall toprak nem rejimi belirleme modeline göre tipik aridik ile zayıf aridik (Typic Aridic - Weak Aridic) arasında değiştiği belirtilmiştir.

\subsection{Kartografik materyaller ve kullanılan yazılımlar}

Çalışmada, proje alanına ait 1:25.000 ölçekli Konya L28b1, L28b4 ve K28c4 pafta kodlu topografik haritaları, eski büyük toprak gurubu düzeyinde sayısal toprak haritaları, MTA Genel Müdürlüğünce hazırlanan Konya ili sayısal jeoloji haritası, 2013 yılına ait $2.5 \mathrm{~m}$ spektral çözünürlüklü Quickbrid uydu görüntüsü ve alanın sayısal yükselti modeli temel kartografikler olarak kullanılmıştır. Alana ait raster verilerin işlenmesinde Erdas Imagine 8.4 (ERDAS, 2004), vektörel verilerin sorgu ve analizlerinde, toprak ve arazi uygunluk sınıflarının dağılım haritalarının çiziminde ArcGIS 9.3 (ESRI, 2010) yazılımları kullanılmıştır.

\subsection{Büro, arazi ve laboratuvar çalışmaları}

Çalışma, topraklarının seri düzeyinde özelliklerinin belirlenmesi, toprak taksonomisine (Soil Survey Staff, 1999) göre sınıflamasının yapılması ve CBS ortamında toprak haritasının oluşturulması amacıyla; büro, arazi ve laboratuvar olmak üzere 3 aşamada gerçekleştirilmiştir. Büro çalışmasında topografik harita, uydu görüntüsü ve sayısal yükselti modeli kullanılarak alanda yayılım gösteren farklı fizyografik üniteler, eğim, rölyef, bakı ve arazi şekilleri çıkartılmışır. Fizyografik üniteler arazi örtüsü ve jeolojik veriler ile birleştirilerek farklı ana materyal ve farklı fizyografya üzerinde oluşmuş topraklar tespit edilmiş ve geçici toprak serilerini içeren taslak toprak haritası oluşturulmuştur. Verilerin birlikte değerlendirilmesi ve ön arazi çalışması sonucu etüd alanında farklılık gösterebilecek toprak sınırlarına ait profil noktaları seçilmiştir. Belirlenen olası farklı özellikteki topraklarda daha önceden belirlenen koordinatlara göre arazide Yer Belirleme Aleti (GPS) 
kullanarak 10 farklı profil çukuru açılmış ve 6 toprak serisine ait genetik horizon esasına göre morfolojik tanımlamalar yapılarak 28 horizon örneklenmiştir. Alınan toprak örnekleri fiziksel ve kimyasal analizler için laboratuvara getirilmiştir. Proje alanı topraklarının morfolojik özelliklerinin incelenip dağılım alanlarının belirlenmesi amaciyla burgu kontrolü, örneklemeler ve sınıflandırma çalışması için (Soil Science Division Staff, 2017) talimatları kullanılmıştır. Laboratuvar aşamasında Bünye (Bouyoucos, 1951), hacim ağırlığı (Black, 1965), tarla kapasitesi ve solma noktasi (Richards, 1954), katyon değişim kapasitesi (Rhoades, 1982), değişebilir katyonlar (Rhoades, 1982), kireç (Soil Survey Lab. Staff, 2004), pH - elektriksel iletkenlik (Soil Survey Lab. Staff, 2004), organik madde (Jackson, 1979), değişebilir potasyum (K) (Soil Survey Lab. Staff, 2004), toplam azot, (Bremner, 1965), yarayışlı fosfor (P) (Olsen ve ark., 1982) ve mikro besin element (Fe, $\mathrm{Mn}, \mathrm{Cu}, \mathrm{Zn}$ ) (Lindsay ve Norvell, 1978) metotları kullanılarak yapılmıştır. Arazi çalışmaları ve laboratuvar analizleri değerlendirilip topak sınırları için gerekli düzeltmeler yapılmış ve proje alanına ait toprak özelliklerini içeren CBS veri tabanını oluşturulmuştur.

\subsection{Arazi değerlendirme aşaması}

Etüd alanında belirlenen Aridisol ordosuna ait toprakların FAO Toprak Verimlilik İndeksine göre tarımsal kullanıma uygunluk sınıfları belirlenmiştir. Toprak Verimlilik İndeksi, toprağın mevcut üretkenlik kapasitesini ve potansiyel verimliliğini belirlemek için geliştirilmiş parametrik bir arazi değerlendirme modelidir (Riquier ve ark., 1970). Bu yaklaşım, her biri 0 ile 100 arasında sayısal bir değer verilen 10 faktöre dayalı bir indis hesaplanmasını kapsamaktadır (Verheye, 2009). Bu faktörlerin çarpımı ile elde edilen puan beş tarımsal uygunluk sınıfinda değerlendirilmektedir (Çizelge 1). Toprak verimlilik indeks formülü ve parametre açılımları aşağıda sunulmuştur.

$$
S P R=\frac{H \times D \times P \times T \times N \times S \times O \times A \times M \times E}{100^{9}}
$$

Burada,

Toprak verimlilik indeksi (SPR), Toprak Nem Rejimi (H), Drenaj (D), Toprak Derinliği (P), Tekstür/Strüktür (T), Baz Saturasyonu (N), Çözülebilir Tuzlar (S), Organik madde içeriği (O), Katyon Değişim Kapasitesi (A), B horizonunda değişebilir katyonlar (M), ve Eğim (E) olarak tanımlanmış Riquier ve ark., (1970)' e göre puanlanmıştır.
Çizelge 1. Toprak verimlilik indeksi son skorun değerlendirilmesi

Table 1. Evaluation of soil fertility index final score

\begin{tabular}{ccc}
\hline Uygunluk Sinıf & Skor & Potansiyel \\
\hline Çok iyi & $65-100$ & I \\
İyi & $35-64$ & II \\
Orta & $20-34$ & III \\
Zayıf & $8-19$ & IV \\
Çok zayıf & $0-7$ & V \\
\hline
\end{tabular}

\section{Bulgular ve Tartışma}

Beşgözler proje alnında kurulan toprak serileri, toprak etüd ve haritalama metodolojisine uygun olarak tanımlanan toprak profilleri ve çevresel özelliklerine göre belirlenmiştir. Çalışma alanında açılan 10 adet toprak profilinin incelenmesi ve burgu kontrollerine göre dağılımlarının belirlenmesi sonucu bölge toprakları 6 adet seriye ayrılmıştır. Serilere ait toprakların tamamı alüvyal ana materyal üzerinde oluşmuş olup, toprakların seri ayrımı alüvyal ana materyalin niteliği, toprakların bulunduğu fizyoğrafya, morfolojik özellikler ve farkl11ıklar, pedojenik oluşumlar ve fiziksel-kimyasal analiz sonuçlarının değerlendirilmesine göre yapılmıştır. Çalışma alanı, 6 seri ve bu serilerin toprak derinliği, üst toprak tekstürü, eğim, drenaj, taşll1ık, erozyon fazlarından oluşan 79 haritalama birimi ile temsil edilmiştir. Tanımlanan ve gerçek sınırları çizilen toprak serileri Yenicekaya, Bayramlı, Göğemiçi, Hüyük, Eski Gözlü ve Kabacalı olarak adlandırılmıştır (Çizelge 2)..

Çizelge 2. Toprak birlik haritası lejantı

Table 2. Soil unity map legend

\begin{tabular}{|c|c|c|c|}
\hline Lejand & Fizyoğrafya & Seri & Profil \\
\hline YDA & $\begin{array}{c}\text { Yan Dere } \\
\text { Alüvyalleri }\end{array}$ & $\begin{array}{c}\text { Yenicekaya(Yk), } \\
\text { Bayraml(By), }\end{array}$ & P7, P9 \\
\hline ENTR & $\begin{array}{l}\text { Eski Nehir } \\
\text { Terasları }\end{array}$ & Göğemiçi(Gg) & P4 \\
\hline TD & $\begin{array}{c}\text { Taşkın } \\
\text { Düzlükleri }\end{array}$ & Hüyük(Hy) & P6 \\
\hline ÇA & $\begin{array}{c}\text { Çamur } \\
\text { Akıntıları } \\
\text { (Bajadalar) }\end{array}$ & Eski Gözlü(Eg) & P3 \\
\hline ÜEA & $\begin{array}{l}\text { Üst Etek } \\
\text { Araziler }\end{array}$ & Kabacalı(Kb) & P8 \\
\hline
\end{tabular}

Hazırlanan toprak haritasının ve fizyoğrafik dağılımın birlikte okunabilmesi, toprakların dağılımlarının ve aralarındaki ilişkilerin daha iyi görülüp anlaşılması amacıyla 1:115.000 ölçekli "Toprak Birlik Haritası" oluşturulmuştur (Şekil 3). Beşgözler proje alanınım toprak taksonomisine göre \% 38'i (1950 ha) Aridisol ordosunda sınıflandırılmış olup \%7.25'i Eski Gözlü ve $\% 92.75$ 'i Bayramlı serisinde tanımlanmıştır (Şekil 4). Aridisol ordosunda temsil edilen topraklar Bayramlı ve Eski Gözlü serilerinde 23 haritalama biriminde dağılım göstermektedir (Çizelge $3)$. 


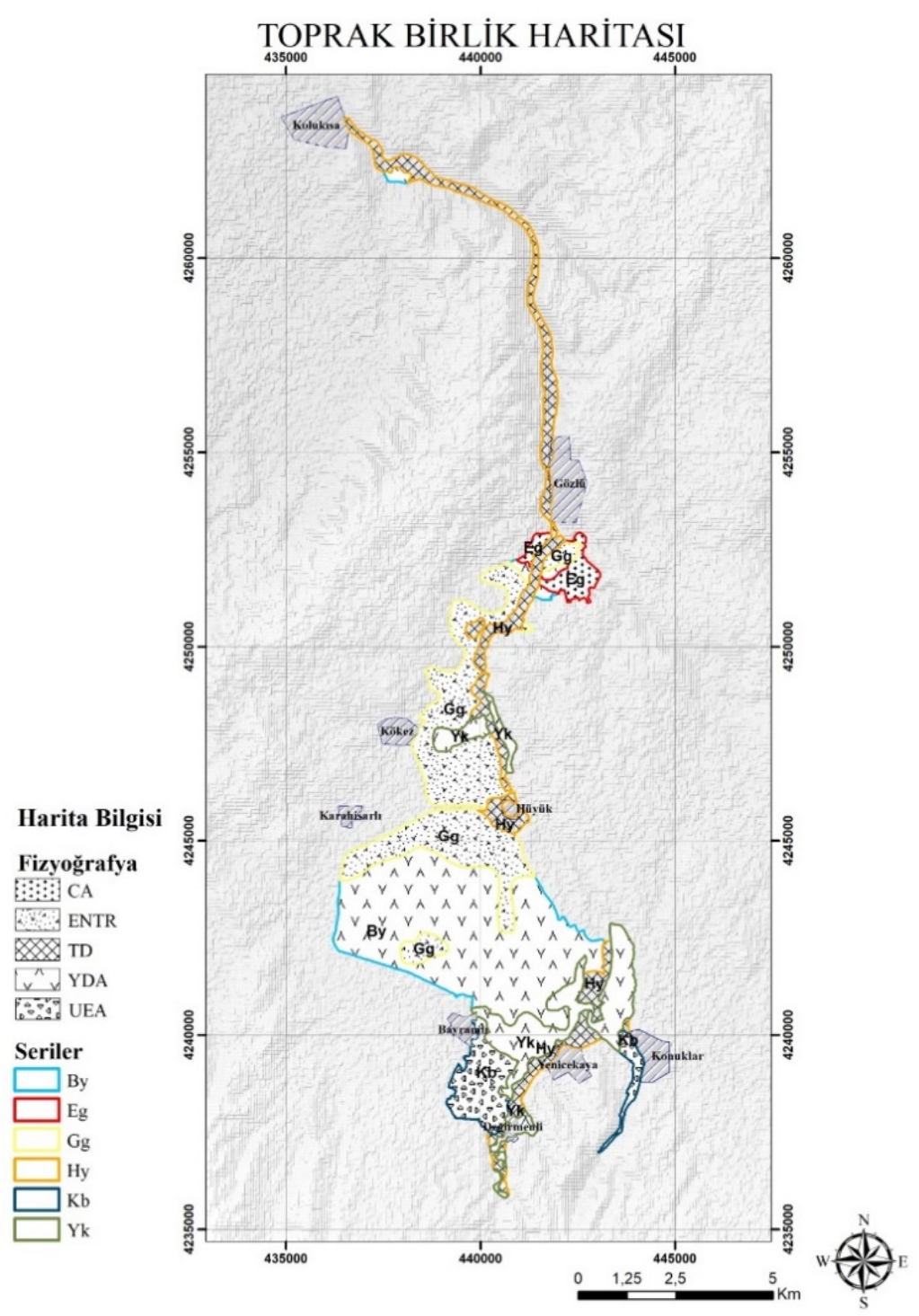

Şekil 3. Beşgözler proje alanı toprak birlik haritası Figure 3. Soil unity map of beşgözler project area

Çizelge 3. Çalışma alanı aridisol ordosu alt toprak sınıfları Table 3. Aridisol subgroups of study area

\begin{tabular}{cccccc}
\hline Ordo & Alt Ordo & Büyük Grup & Alt Grup & Familya & Seri Adı \\
\hline Aridisol & Cambids & Haplocambids & Typic Haplocambids & Killi, kireçli, mesic & Eski Gözlü \\
Aridisol & Calcids & Haplocalcids & Typic Haplocalcids & Killi, kireçli, kaba maddeli mesic & Bayramlı \\
\hline
\end{tabular}




\begin{tabular}{|c|c|c|c|c|}
\hline & Eski Gözlü Serisi (Eg) & Hor. & $\begin{array}{l}\text { Der. } \\
(\mathrm{cm})\end{array}$ & Tanım \\
\hline--- & & Ap & $0-22$ & $\begin{array}{l}\text { Kuru iken parlak kahverengi ( } 7.5 \text { YR 5/6), nemli iken } \\
\text { kırmızımsı kahverengi ( } 5 \text { YR 4/8); kil; orta, küçük, } \\
\text { granüler strüktür; kuru iken sert, nemli iken sıkı; yaş iken } \\
\text { yapıșkan ve plastik; çok kireçli; çok az taşlı, ince çok } \\
\text { seyrek kökler; belirgin düz sımırl.. }\end{array}$ \\
\hline $\begin{array}{l}\text { B1w } \\
----\end{array}$ & & B1w & $22-53$ & $\begin{array}{l}\text { Kuru iken kırmızımsı kahverengi (5 YR 4/6), nemli iken } \\
\text { kırmızımsı kahverengi (5 YR 4/6); kil; orta, orta, köşeli } \\
\text { blok strüktür; kuru iken çok sert, nemli iken sıkı; yaş } \\
\text { iken yapışkan ve plastik; çok kireçli; taşsız; çok seyrek } \\
\text { çok ince saçak kökler; geçişli düz sınırl. }\end{array}$ \\
\hline B2w & & $\mathrm{B} 2 \mathrm{w}$ & $\begin{array}{l}53- \\
112\end{array}$ & $\begin{array}{l}\text { Kuru iken parlak kırmızımsı kahverengi (5 YR } 5 / 6 \text { ), } \\
\text { nemli iken kırmızımsı kahverengi ( } 5 \text { YR 4/8); kil; orta, } \\
\text { orta, köşeli blok strüktür; kuru iken çok sert, nemli iken } \\
\text { sıkı; yaş iken yapışkan ve plastik; çok kireçli, küçük çok } \\
\text { seyrek yuvarlak açık gri düzensiz dağılmış kireç cepleri; } \\
\text { taşsız; köksüz; geçişli düz sınırlı. }\end{array}$ \\
\hline $\mathrm{C}$ & & $\mathrm{C}$ & $112+$ & $\begin{array}{l}\text { Kuru iken kırmızımsı kahverengi ( } 5 \text { YR } 4 / 8 \text { ), nemli iken } \\
\text { kırmızımsı kahverengi ( } 5 \text { YR 4/8); kil; masif strüktür; } \\
\text { kuru iken çok sert, nemli iken sıkı; yaş iken yapışkan ve } \\
\text { plastik; çok kireçli, orta orta yoğun açı gri düzensiz } \\
\text { dağılmış yuvarlak kireç cepleri. }\end{array}$ \\
\hline
\end{tabular}

Şekil 5. Eski gözlü (Eg) serisi örnek profili ve horizon tanımlamaları Figure 5. Sample profile of the Eski gözlü (Eg) series and horizon descriptions

Çizelge 4. Eski gözlü serisi (Eg) topraklarının fiziksel ve kimyasal analiz sonuçları

Table 4. Physical and chemical analysis results of Eski gözlü series (Eg) soils

\begin{tabular}{|c|c|c|c|c|c|c|c|c|c|c|c|c|}
\hline \multirow[b]{2}{*}{ Horizon } & \multirow[b]{2}{*}{$\begin{array}{l}\text { Derinlik } \\
\text { (cm) }\end{array}$} & \multirow[b]{2}{*}{$\begin{array}{c}\mathrm{pH} \\
(1: 1)\end{array}$} & \multirow[b]{2}{*}{$\begin{array}{c}\text { Kireç } \\
(\%)\end{array}$} & \multirow{2}{*}{$\begin{array}{c}\text { EC } \\
\left(\mu \mathrm{mhos}^{-} \mathrm{cm}^{-}\right. \\
\left.{ }^{1}\right)\end{array}$} & \multirow[b]{2}{*}{$\begin{array}{l}\text { DSY } \\
(\%)\end{array}$} & \multicolumn{3}{|c|}{ Tekstür (\%) } & \multirow{2}{*}{\multicolumn{2}{|c|}{$\begin{array}{c}\text { Tekstür } \\
\text { Sinıfi }\end{array}$}} & \multirow{2}{*}{$\begin{array}{l}\text { Hacim } \\
\text { Ağırl. } \\
\left(\mathrm{g} / \mathrm{cm}^{3}\right)\end{array}$} & \multirow{2}{*}{$\begin{array}{c}\text { Fay. } \\
\text { Su } \\
(\mathrm{V}, \\
\%)\end{array}$} \\
\hline & & & & & & Kum & Silt & Kil & & & & \\
\hline Ap & $0-22$ & 7.61 & 18.20 & 832 & 0.23 & 28.83 & 29.17 & 42.0 & & $\mathrm{C}$ & 1.21 & 13.68 \\
\hline B1w & $22-53$ & 7.82 & 17.88 & 579 & 0.12 & 20.80 & 12.00 & 67.2 & & $\mathrm{C}$ & 1.26 & 15.65 \\
\hline $\mathrm{B} 2 \mathrm{w}$ & 53-112 & 7.9 & 19.85 & 502 & 0.15 & 23.00 & 20.00 & 57.0 & & $\mathrm{C}$ & 1.26 & 14.65 \\
\hline $\mathrm{C}$ & $112+$ & 7.94 & 22.18 & 473 & 0.22 & 24.80 & 16.00 & 59.2 & & $\mathrm{C}$ & 1.28 & 14.59 \\
\hline \multirow{2}{*}{ Horizon- } & \multicolumn{4}{|c|}{ Değişebilir Katyonlar (me/100 g) } & KDK & \multirow{2}{*}{$\begin{array}{c}\text { Org. M } \\
\text { (\%) }\end{array}$} & \multirow{2}{*}{$\begin{array}{l}1 \text { T.N } \\
(\%)\end{array}$} & \multicolumn{5}{|c|}{$\mathrm{mg} \mathrm{kg}^{-1}$} \\
\hline & $\mathrm{Na}^{+}$ & $\mathrm{K}^{+}$ & $\mathrm{Ca}^{++}+$ & $\mathrm{Mg}^{++}$ & (me/100g) & & & $\mathrm{P}$ & K & B & $\mathrm{Cu} \quad \mathrm{Fe}$ & $\mathrm{Mn} \mathrm{Zn}$ \\
\hline Ap & 0.09 & 1.14 & 39 & & 40.40 & 1.80 & 0,21 & 12.02 & 447.73 & 0.227 & 1.524 .36 & 13.910 .26 \\
\hline B1w & 0.05 & 0.86 & 39 & & 40.73 & 1.09 & 0,13 & 3.08 & 336.08 & $<0.10$ & 1.646 .98 & 14.410 .09 \\
\hline $\mathrm{B} 2 \mathrm{w}$ & 0.06 & 0.72 & 38 & & 39.45 & 0.89 & 0,10 & 2.65 & 283.75 & $<0.10$ & 1.848 .82 & 15.170 .05 \\
\hline $\mathrm{C}$ & 0.07 & 0.60 & 33 & & 34.10 & 0.58 & 0,07 & 3.28 & 236.71 & $<0.10$ & 1.226 .25 & 10.860 .04 \\
\hline
\end{tabular}




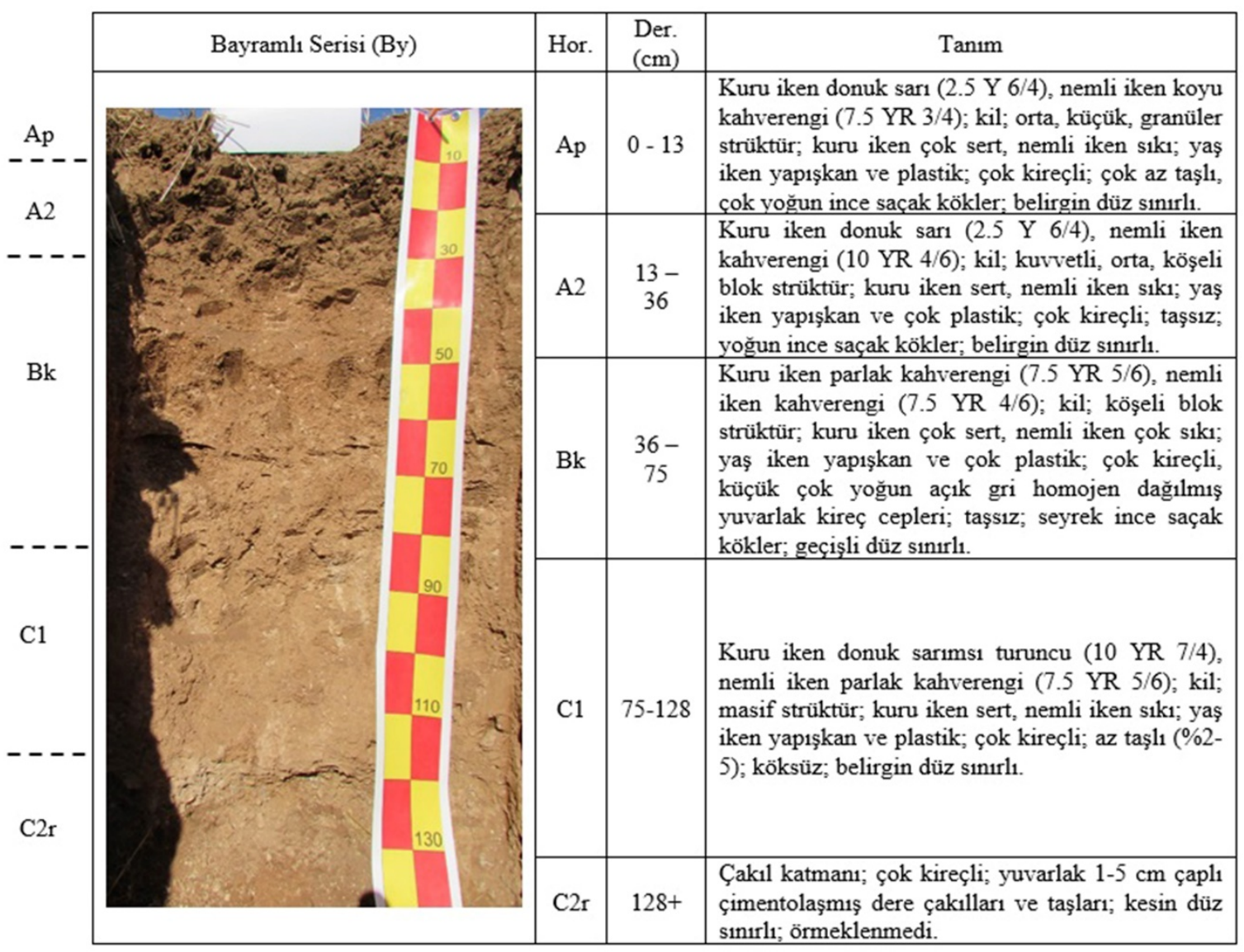

Şekil 6. Bayramlı (By) serisi örnek profili ve horizon tanımlamaları

Figure 6. Sample profile of the Bayramlı (By) series and horizon descriptions

Çizelge 5. Bayramlı serisi (By) topraklarının fiziksel ve kimyasal analiz sonuçları

Table 5. Physical and chemical analysis results of Bayraml series (By) soils

\begin{tabular}{|c|c|c|c|c|c|c|c|c|c|c|c|c|c|}
\hline \multirow{2}{*}{ Horizon } & \multirow{2}{*}{$\begin{array}{l}\text { Derinlik } \\
(\mathrm{cm})\end{array}$} & \multirow{2}{*}{$\begin{array}{c}\mathrm{pH} \\
(1: 1)\end{array}$} & \multirow{2}{*}{$\begin{array}{c}\text { Kireç } \\
(\%)\end{array}$} & \multirow{2}{*}{$\begin{array}{c}\text { EC } \\
\left(\mu \mathrm{mhos} \mathrm{cm}^{-1}\right)\end{array}$} & \multirow{2}{*}{$\begin{array}{l}\text { DSY } \\
(\%)\end{array}$} & \multicolumn{3}{|c|}{ Tekstür (\%) } & \multirow{2}{*}{\multicolumn{2}{|c|}{$\begin{array}{l}\text { Tekstür } \\
\text { Sinıfi }\end{array}$}} & \multirow{2}{*}{$\begin{array}{l}\text { Hacim Ağırl. } \\
\left(\mathrm{g} / \mathrm{cm}^{3}\right)\end{array}$} & \multirow{2}{*}{\multicolumn{2}{|c|}{$\begin{array}{c}\text { Fay. Su } \\
(\mathrm{V}, \%)\end{array}$}} \\
\hline & & & & & & Kum & Silt & Kil & & & & & \\
\hline Ap & $0-13$ & 7.78 & 20.31 & 827 & 0.503 & 22.13 & 18.67 & 59.2 & 20 & & 1.24 & & 12.68 \\
\hline A2 & $13-36$ & 7.96 & 19.07 & 618 & 1.286 & 22.13 & 14.67 & 63.2 & 20 & & 1.26 & & 15.33 \\
\hline $\mathrm{Bk}$ & $36-75$ & 7.97 & 39.63 & 543 & 0.917 & 22.13 & 12.00 & 65.8 & 37 & & 1.27 & & 15.79 \\
\hline $\mathrm{C} 1$ & $75-128$ & 8.1 & 30.04 & 491 & 0.546 & 24.80 & 16.00 & 59.2 & 20 & & 1.25 & & 17.45 \\
\hline \multirow{2}{*}{ Horizon- } & \multicolumn{4}{|c|}{ Değişebilir Katyonlar (me/100 g) } & \multirow{2}{*}{$\begin{array}{c}\text { KDK } \\
\text { (me/100g) }\end{array}$} & \multirow{2}{*}{$\begin{array}{l}\text { Org. M. } \\
(\%)\end{array}$} & \multirow{2}{*}{$\begin{array}{l}\text { T.N } \\
\text { (\%) }\end{array}$} & \multicolumn{6}{|c|}{$\mathrm{mg} \mathrm{kg}^{-1}$} \\
\hline & $\mathrm{Na}^{+}$ & $\mathrm{K}^{+}$ & $\mathrm{Ca}^{++}$ & $+\mathrm{Mg}^{++}$ & & & & $\mathrm{P}$ & K & B & $\mathrm{Cu}$ & Mn & $\mathrm{Zn}$ \\
\hline Ap & 0.16 & 1.09 & & .86 & 31.11 & 1.91 & 0,22 & 15.70 & 425.63 & 0.061 & 1.295 .97 & 16.58 & 80.26 \\
\hline A2 & 0.44 & 0.66 & & .75 & 31.83 & 1.68 & 0,19 & 12.58 & 257.93 & 0.062 & 1.436 .59 & 14.47 & $7 \quad 0.19$ \\
\hline $\mathrm{Bk}$ & 0.26 & 0.49 & & .95 & 28.71 & 0.46 & 0,05 & 3.30 & 191.08 & 0.110 & 1.417 .70 & 10.46 & 0.04 \\
\hline C1 & 0.13 & 0.39 & & .97 & 23.49 & 0.28 & 0,03 & 3.11 & 153.85 & 0.213 & 0.606 .23 & 4.49 & 0.03 \\
\hline
\end{tabular}


Eski Gözlü serisine ait topraklar Bajadalar üzerinde oluşmuş, düz-düze yakın ve hafif eğimli, düz bir topoğrafyaya ve çeşitli derinliklere sahip topraklardır. Profil boyunca çok kireçlidir. Profilde sekonder kireç birikimi genelde kireç cepleri halinde C horizonunda görülmekte ve ana materyal kaynaklı olması nedeniyle Kalsik horizon tanımlaması için yeterli şartları sağlamamaktadır. Yüzey horizonlarında ince çok seyrek kök gelişimi görülmektedir. Eski Amerikan Toprak Sınıflama Sistemine göre Kırmızımsı Kahverengi büyükalt gruplarında seri düzeyinde ayrılmasını gerektirmiştir. Eski Gözlü serisi örnek profili ve tanımlamaları Şekil 5'de, toprakların fiziksel - kimyasal analiz sonuçları Çizelge 4'de sunulmuştur.

Bayramlı serisine ait topraklar ova niteliği kazanmış yan dere alüvyalleri üzerinde oluşmuş, çeşitli eğimlerde, düz bir topoğrafyaya sahip, oldukça derin ve derin topraklardır. Profil boyunca yüksek kireç içeriğ i göstermektedir. Yüzey horizonlarında çok yaygın ince kök gelişimi görülmektedir. Eski Amerikan Toprak Sınıflama Sistemine göre Kırmızımsı Kahverengi büyük toprak grubu olarak tanımlanan kil- killi tın tekstüre sahip seri, toprak oluş işlemlerinin bölgeye göre daha uzun süre etkisinin gözlemlendiği Kalsik B horizonu varlığı ve zamanla taşınıp birikmiş olan çakıl katmanı ile Typic Haplocalcids alt grupunda farklı bir seri olarak sınıflandırılmıştır. Bayramlı serisi örnek profili ve tanımlamaları Şekil 6'da, toprakların fiziksel - kimyasal

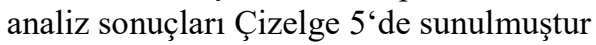

Burgu kontrolleri ile kesin toprak sinırlarının belirlenmesi aşamasında serilerin bazı bölgelerinde az ( $\%$ 2-5) ve orta derecede (\% 5-15), 6-20 cm çaplı taşlık problemi olduğu ve toplam alanın $12 \%$ sinde (234 ha) dağılım gösterdiği belirlenmiştir. Taşlık problemi belirlenen arazilerin tamamında kültür bitkisi yetiştiriciliği yapılmaktadır. Eski Gözlü serisinin bazı bölgelerinde yetersiz drenaj koşulları tespit edilmiştir. Yaklaşık 293 ha alan kaplayan bu bölgeler toplam alanın \%15'ini etkilemektedir. Çalışma alanı toprakları ağır bünyeli olup, kil içeriği bazı bölgelerde $>\% 60$ ' lara ulaşmaktadır. Bu durum toprak işleme zamanının çok iyi seçilmesini, toprakların uygun düzeyde su ve hava içerdiği tavlı dönemlerinde tohum yatağı hazırlamasını gerektirmektedir. Killi toprakların, toprak tavının yetersiz olduğu dönemlerde işlenmeleri fiziksel yapılarında bozulmalar meydana getirirken, fazla nemli koşullarda işlenmeleri ise topraklarda iri kesekler meydana getirmektedir. Nitekim kil içeriği yüksek toprakların en uygun işleme zamanının tarla kapasitesine yakın seviyesindeki nem içeriğinde olması gerektiği belirtilmiştir (Gülser ve Candemir, 2006). Çalışma alanı topraklarının hacim ağırlığı değerlerinin (1.21-1.28 g cm-3) killi topraklar için uygun aralıklarda olduğu (Pagliai ve ark., 2003), özellikle sulu tarım alanlarında yoğun tarla trafiğinden kaynaklanan ve toprak işleme - yönetim uygulamalarında büyük sorun arz eden toprak sıkışmasının (Şeker ve Işıldar, 2000; Botta ve ark., 2010), meydana gelmediği belirlenmiştir. Özellikle sulu tarım alanlarında, bitkilerin sulama zamanının belirlenmesi için büyük öneme sahip olan yarayışlı su içeriği değerleri proje alanında $150 \mathrm{~cm}$ toprak derinliğinde $\% 12.68-\% 17.45$ değerleri arasında değişmekte olup ortalaması $\% 15.98$ olarak belirlenmiştir. Etüt alanı topraklarının $\mathrm{pH}$ ve $\mathrm{EC}$ (elektriksel iletkenlik) değerleri incelendiğinde EC, 473 - 832 umhos cm-1 aralığında değişmekte olup Jones Jr,( 2001)'e göre bölgede tuzluluk problemi belirlenmemiştir. Ancak makro ve mikro besin elementlerinin yarayışlılığıyla doğrudan ilişkili olan $\mathrm{pH}$, yüzeyde $(0-30 \mathrm{~cm}) 7.61-7.96$ değerleri arasında hafif alkalin sınırında değişmekte iken alt horizonlarda 8.10 değerlerinde alkalin özellik göstermektedir. Benzer şekilde bölge toprakları 0-30 cm derinlikte \%17.88 -\% 20.31 değerleri arasında yüksek kireç içermektedir. $\mathrm{Bu}$ durum başta fosfor, çinko ve demir olmak üzere bitkilerde besin noksanlıklarına neden olmaktadır (Kacar ve Katkat, 2011). Fazla kireç içeriğinin olumsuzluklarını tolere edebilmek için topraklara hümik asit uygulaması ile birlikte dengeli gübreleme ve uygun gübreleme teknikleri önerilmektedir (Zengin ve Gezgin, 2013). Topraklarının değişebilir katyon içerikleri potasyum (K) (0.325 - $1.271 \mathrm{me} / 100 \mathrm{~g})$, kalsiyum (Ca) + magnezyum (Mg) (27.97-39.82 me/100 g ) yönünden (FAO, 1990)'a göre yeter - fazla sinıfina girmektedir. Değişebilir sodyum yüzdesi (DSY) değerleri incelendiğinde drenaj problemi tespit edilen alanlar bulunmasına rağmen bölge için potansiyel bir sodikleşme problemi oluşturmamaktadır. Etüt alanı içerisinde yüzey toprağının $\mathrm{pH}$ değerlerinin de 8.5 'in altında belirlenmesi, mevcut durumda bir alkalilik problemi olmadığını göstermektedir. Toprak verimliliğinin en önemli göstergelerinden olan organik madde içeriği bölge toprakları için değerlendirildiğinde $0-30 \mathrm{~cm}$ toprak derinliğinde $\% 1.26-\% 1.8$ arasında değişmekte olup, derinliğe bağlı olarak alt horizonlarda azalmaktadır. Belirlenen organik madde içerikleri K.O.P. bölgesi topraklarının genelinde benzerlik göstermekte olup yeşil gübrelemenin yapılamaması, münavebeye önem verilmemesi ve kuraklık bu durumun en önemli sebepleridir (Zengin ve Gezgin, 2013). Bölge topraklarının yarayışlı fosfor (P) içeriği alakalin reaksiyonlu topraklar için (Ulgen ve Yurtsever, 1984)' e göre değerlendirildiğinde 12.02 - 15.70 mg kg-1 aralığında yeterli olarak belirlenmiştir. Benzer şekilde azot $(\mathrm{N})$ içerikleri \%0.13 - \%0.22 arasında değişmekte olup bölge toprakları için yeterli düzeydedir (Kacar ve Katkat, 2011). Serilerin mikro element kapsamları (Lindsay ve Norvell, 1978)'e göre bakır $(\mathrm{Cu})$ ve mangan (Mn) sirasiyla $1.29-1.52 \mathrm{mg} \mathrm{kg}-1$ ve $14.41-$ $16.58 \mathrm{mg}$ kg-1 değerleri arasında değişmekte olup fazla olarak belirlenmiştir. Demir (Fe) Eskigözlü serisinde orta seviyede (5.67 mg kg-1), Bayramlı serisinde yeterli (6.28 mg kg-1) bulunmuştur. Çinko (Zn) içeriği 0.24$0.48 \mathrm{mg}$ kg-1 değerleri ile az olarak belirlenmiştir.

Beşgözler proje alanında belirlenen Aridisol ordosuna ait toprakların haritalama birimi bazında FAO toprak verimlilik indeksine göre değerlendirmesi sonucu; II. sınıf (S2) iyi nitelikli tarım arazileri \%60.50, 
III. sinıf (S3) orta nitelikli tarım arazileri \%39.32, IV. sınıf zayıf nitelikli tarım arazileri ise sadece Eski Gözlü serisinde \%0.18 oranında alansal dağılım gösterdiği belirlenmiştir (Çizelge 6).

Çizelge 6. Serilerin toprak verimlilik indeksine göre alansal ve oransal dağılımları

Table 6. Areal and proportional distributions of series according to soil fertility index

\begin{tabular}{llllcc}
\hline Nitelik & Sinıf & \multicolumn{2}{c}{ Eski Gözlü Serisi } & \multicolumn{2}{c}{ Bayramlı Serisi } \\
\cline { 3 - 6 } & & $\begin{array}{l}\text { Alan } \\
\text { (ha) }\end{array}$ & $\begin{array}{l}\text { Oran } \\
\text { (\%) }\end{array}$ & $\begin{array}{c}\text { Alan } \\
\text { (ha) }\end{array}$ & $\begin{array}{c}\text { Oran } \\
\text { (\%) }\end{array}$ \\
\hline Cok iyi & I & - & - & - & - \\
İyi & II & 52.12 & 2.67 & 1127.71 & 57.83 \\
Orta & III & 20.23 & 1.04 & 746.42 & 38.28 \\
Zayıf & IV & 3.54 & 0.18 & - & - \\
Çok & V & - & - & - & \\
Zayıf & & & & & \\
\hline
\end{tabular}

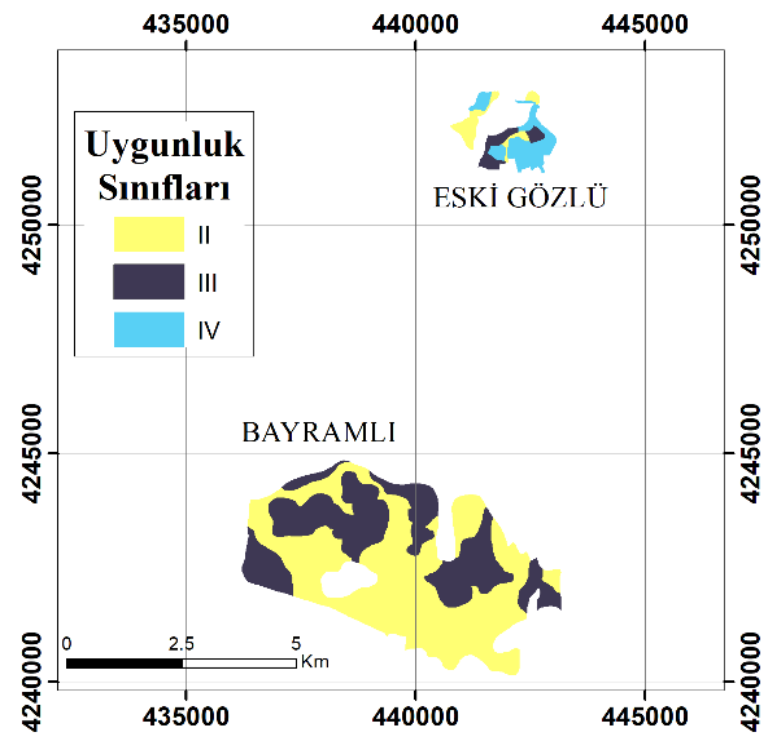

Şekil 7. Toprak verimlilik indeksine göre Aridisollerin tarımsal uygunluk dağılımları

Figure 7. Agricultural suitability distributions of aridisols according to soil fertility index

Bölge Aridisolleri I. sınıf (S1) seçkin tarım arazisi niteliği göstermemektedir. "Zayıf" tarımsal uygunluk sınıfına giren alanlar yaklaşık 3.5 ha büyüklüğünde olup, ağır bünye, sı̆̆ toprak derinliğì, taşlık, drenaj bozukluğu, organik madde yetersizliği ve hafif eğim tarımsal üretimi sınırlayıcı faktörler olarak belirlenmiştir. "Orta" uygunluk sinıfinda tanımlanan alanlar her iki seride farklı büyüklüklerde dağılım göstermektedir. $\mathrm{Bu}$ alanların sığ toprak derinliği, ağır bünye ve hafif eğim faktörlerine sahip olmaları "orta" uygunluk sınıfında değerlendirilmelerini gerektirmiştir. Ayrıca bu sınıfa giren alanlarda derin ve killi-tın bünyede topraklar olmasına karşın taşlık problemi ve yetersiz drenaj tarımsal ürün yetiştiriciliğini kısıtlayıcı faktörler olarak belirlenmiştir. Ancak potansiyel bir problem olarak değerlendirilen taşlık probleminin giderilmesi ve yetersiz drenaj belirlenen alanlarda fazla suyun uzaklaştırılması ile bu araziler "iyi" uygunluk niteliğinde değerlendirilebilir. "İyi” nitelikli alanlarda tarımsal yetiştiricilik açısından hafif yüzey taşlılığı ve ağır bünye dışında kısıtlayıcı faktör bulunmamaktadır. Etüt alanında tanımlanan Aridisollerin Toprak Verimlilik İndeksine göre oluşturulan tarımsal uygunluk haritası Şekil. 7'de sunulmuştur. Aridisol ordoları derin ve düz topografyalı topraklar barındırmasına rağmen uygunluk sınıflamasında değerlendirilen faktörler (yıllık nem indeksi ve kök bölgesi strüktürü) ilgili alanların model hesaplamaları sonucu "çok iyi" uygunluk sınıfında değerlendirilmemesini gerektirmiştir. Bölge Aridisollerine ait bazı haritalama birimlerinde belirlenen tarımsal üretimi kısıtlayıcı faktörlerin (yetersiz drenaj, taşlık, erozyon derecesi) etki derecelerinin azaltıla bileceği ve özellikle toprak organik maddesini arttırıcı önlem ve uygulamaların yapılması ile bu alanların daha nitelikli tarımsal kullanıma uygunluk sinıflarında değerlendirilebileceği anlaşılmaktadır. Nitekim Dünya'da toprak verimlilik indeksi, mevcut ve potansiyel tarımsal arazi kullanımlarını değerlendirmenin yanında (Tekwa ve ark., 2011), arazi bozulma koşullarının etki derecelerini belirlemek için tercih edilen önemli bir metottur (Kawy ve Ali, 2012). Sürekli sulanan Nil deltasında arazi bozulma süreçlerinin, toprak verimliliğine olan etkilerini incelemek için toprak verimlilik indeksi kullanılmış ve çalışma sonucu Nil deltasının çevresinde 1975 - 2011 yılları arasında alanın \%69.73 oranında arazi bozulma süreçlerinden aşırı derecede etkilendiği ve bu etkinin toprak kalitesini önemli derecede düşürdüğü belirtilmiştir (Kawy ve Ali, 2012). Toprak verimlilik indeksi farklı arazi değerlendirme metotları ile İspanya'nın yoğun tarım yapılan Castilla-La Mancha bölgesinde ürün verimleri ile karşılaştırılmış ve modelin toprakların mevcut niteliklerini belirlemede başarılı olduğu bildirilmiştir (González-Quiñones ve ark., 2007). Çalışma sonucu elde edilen bulgular ve geçmiş araştırma sonuçları Toprak Verimlilik İndeksinin özellikle Ülkemiz tarım topraklarını uygunluk sınıflamalarında alternatif bir yaklaşım olarak değerlendirilebileceğini göstermektedir.

\section{Sonuç}

Türkiye bulunduğu konumu gereği farklı toprak oluşum süreçlerinden etkilenen ve bu sayede çok çeşitli toprak tiplerinin dağılım gösterdiği bir ülkedir. Bu ç̧eşitliği sağlayan önemli faktörlerden biri de faklı iklim bölgelerine sahip oluşudur. Nitekim iklim tipi Toprak Taksonomisinde nem ve sicaklık rejimlerine dayanan bir sinıflandırma kıstası olarak kullanmaktadır. $\mathrm{Bu}$ sayede farklı toprak sinıfları için planlanacak yönetimsel faaliyetlerin iklim özellikleri ile de ilişkilendirilmesine katkı sağlanmaktadır. $\mathrm{Bu}$ durum 
Konya Ovası gibi su kıtllğg çeken ve büyük çaplı projeler ile yeni sulama sahalarının açılacağı Arid bölgelerimiz için büyük önem arz etmektedir. Öyleki 1970 yılı iklim verilerine göre yarı kurak iklim tipinde ve Xeric toprak nem rejiminde tanımlanan Konya Sarayönü bölgesi, 1970-2015 y1lı uzun yıllar ortalama iklim verilerinin Newhall simülasyon modeli kullanılarak değerlendirilmesi sonucu kurak iklim tipi ve Aridik nem rejiminde sinıflanmaktadır. Bu durum araştırmamızda Beşgözler KOP proje sahasında 1950 ha alanın Toprak Taksonomisine göre 2 farklı seride Aridisol ordosunun Typic Haplocalcids (1874.11) ve Typic Haplocambids (75.89 ha) alt toprak gruplarında sınıflandırılmasını gerektirmiștir. Tanımlanan Aridisol ordolarında Toprak Verimlilik İndeksi kullanarak haritalama birimi seviyesinde gerçekleştirilen arazi değerlendirme çalışması sonucu "iyi ve orta" nitelikli araziler \%99 oranında geniş bir dağılım gösterirken, Arid bölgeler için bitki yetiştiriciliğine büyük önem arz eden toprak neminin kısıtlayıcı etkisi nedeniyle "çok iyi" nitelikli elit tarım arazileri belirlenememiştir. $\mathrm{Bu}$ sonucun ileride K.O.P. kapsamında sulamaya açılacak bölge için karar vericiler düzeyinde kurgulanacak planlamalara altlık olarak değerlendirilebileceği öngörülmüştür. Çalışma sonucu belirlenen uygunluk sınıfları ile yer gerçeklerinin gözlemsel karşılaştııılması sonucu Aridisollerin orta ve iyi tarımsal uygunluk sınıflarında kuru şartlarda karlılık sırası ile buğday veya arpa, sulu şartlarda uygunluk sırası ile şeker pancarı, ayçiçeği, mısır veya fasulye yetiştiriciliğinin yapılabileceği önerilmiştir. Aynı zamanda çalışmada kullanılan Toprak Verimlilik İndeksinin arazilerin mevcut durum potansiyelini siniflandırması, yapılabilecek iyileştirmelere yönelik fikirler vermesi, toprak karakteristikleri arasındaki etkileşimleri skorlaması, gelişen CSB teknolojilerine entegre edilebilirliği ve toprakların mevcut verimliliklerini ölçmekle birlikte bazı koruma ve iyileştirme tedbirleri ile arazilerin ulaşabileceği potansiyeli ölçmesi açısından arazi değerlendirme çalışmalarında kullanılması gerektiği önerilmiştir.

\section{Teșekkür}

$\mathrm{Bu}$ çalışma Mert DEDEOĞLU' nun 'Sarayönü Beşgözler K.O.P. Alanı Detaylı Toprak Etüdü ve Farklı Yöntemlerle Arazi Değerlendirmesi” isimli Doktora Tezinin ve Selçuk Üniv. BAP Koordinatörlüğü tarafindan desteklenen 14401018 nolu projenin bir bölümünden hazırlanmış, "1st International GAP Agriculture and Livestock Congress, 2018'de” Özet bildiri olarak sunulmuştur.

\section{Kaynaklar}

Anonim, 2015. http://www.dmi.gov.tr/iklim/

Başayiğit, L., Dinç, U., 2005. Toprak taksonomisine göre toprak iklim rejimleri ve Türkiye toprakları için örnekler. GOÜ Ziraat Fakültesi Dergisi, 22(1): 8391.
Black, C.A., 1965. Methods of soil analysis Part 1: Physical and mineralogical methods; Part 2. Chemical and microbiological properties. American Society Of Agronomy, Inc.; USA.

Blum, W., 1993, Soil protection concept of the Council of Europe and integrated soil research, In: Integrated Soil and Sediment Research: A Basis for Proper Protection. Eds: Springer, p. 37-47.

Botta, G., Tolon-Becerra, A., Lastra-Bravo, X., Tourn, M., 2010. Tillage and traffic effects (planters and tractors) on soil compaction and soybean (Glycine max L.) yields in Argentinean pampas. Soil and Tillage Research, 110(1): 167-174.

Bouyoucos, G.J., 1951. A recalibration of the hydrometer method for making mechanical analysis of soils. Agronomy Journal. 43(9): 434-438.

Bremner, J.M., 1965. Total nitrogen. In. C.A. Black et al (ed). Methods of Soil Analysis. Part 2, Am. Soc .of Agron, 9, 1149-1178.

Çakmaklı, M., 2008. Harran Ovası topraklarının kökeni ve oluşum mekanizmaları (jeoloji ve toprak ilişkileri). Doktora Tezi. Harran Üniversitesi Ziraat Fakültesi, Fen Bilimleri Enstitüsü, Şanlıurfa.

Dengiz, O., 2007. Characteristics and classification of arid region soils: Salt lake specially protected area (Tuz Gölü Turkey). Asian Journal of Chemistry, 19(3): 2316-2324.

Dengiz, O., Kurşun, G., 2018. Arid karasal ekosistem koşulları altında oluşmuş toprakların sınıflaması ve dağılımlarının belirlenmesi. Toprak Su Dergisi, 7(2): $1-11$.

Dengiz, O., Sarığlu, F., 2011. Samsun ilinin potansiyel tarım alanlarının genel dağılımları ve toprak etüd ve haritalama çalışmalarının önemi. Anadolu Tarım Bilimleri Dergisi, 26(3): 241-253.

ERDAS, 2004. 8.7 User's Guide. Leica Geosystems GIS \& Mapping Inc., USA.

ESRI, 2010. ArcGIS user's guide, http://www.esri.com.

FAO, 1976. A Framevork for land evaluation, Soils Bulletin: 32, Food and Agriculture Organization of the United Nations, Rome, Italy.

FAO., 1990. Macronutrient, assessment at the country level: An international study. FAO Soil Bulletin by Mikko Sillanpaa. Rome.

González-Quiñones, V., de la Torre, A., García, M., Polo, A., Jiménez-Ballesta, R., 2007. Application of the FAO quantitative and SINDI methods to assess the quality of different soils in Castilla-La Mancha (Spain). Environmental Geology, 53(3): 527-531.

Gülser, C., Candemir, F., 2006. Ondokuz Mayıs Üniversitesi Kurupelit kampus topraklarının bazı mekaniksel özellikleri ve işlenebilirlikleri. Ondokuz Mayıs Üniversitesi Ziraat Fakültesi Dergisi, 21(2): 213-217.

Jackson, M.L., 1979. Soil chemical analysis-advanced course. 2nd ed, 11th Printing. Published by the author, Madison. 
Jones Jr, J.B., 2001. Laboratory guide for conducting soil tests and plant analysis. CRC press, Washington DC.

Kacar, B., Katkat, A., 2011. Bitki Besleme. Nobel Yayınları (5. Bask1), p1-678, Ankara.

Kapur, S., Aydın, M., Akça, E., Reich, P., 2017. The Soils of Turkey. In: Kapur S, Akça E and Günal H (Eds). Climate Change and Soils.World of Soils Book Series. Springer International Publishing Switzerland. pp. 45-55.

Karlen, D., Andrews, S. ve Doran, J., 2001, Soil quality: current concepts and applications, Advances in Agronomy, 2001(74): 1-40.

Kawy, W.A., Ali, R., 2012. Assessment of soil degradation and resilience at northeast Nile Delta, Egypt: The impact on soil productivity. The Egyptian Journal of Remote Sensing and Space Science, 15(1): 19-30.

Lindsay, W.L., Norvell, W.A., 1978. Development of a DTPA soil test for zinc, iron, manganese, and copper. Soil Science Society of America Journal, 42(3): 421-428.

Mohit, M.A., Ali, M.M., 2006. Integrating GIS and AHP for land suitability analysis for urban development in a secondary city of Bangladesh. Jurnal alam Bina Jillid, 8(1): 1-20.

MTA, 2009. Kadınhanı-Sarayönü-Sülüklü (Konya) dolayının jeolojisi. Maden Teknik Arama Müdürlüğü, Jeoloji Etütleri Dairesi, Kitapçık No:9030, Ankara.

Mueller, L., Schindler, U., Mirschel, W., Shepherd, T. G., Ball, B. C., Helming, K., Rogasik, J., Eulenstein, F., Wiggering, H., 2010. Assessing the productivity function of soils. A review, Agronomy for Sustainable Development, 30(3): 601-614.

Newhall, F., 1972. Calculation of soil moisture regime from climatic records. Inpublished. Soil Conservation Service, USDA. Rev. 4. Washington, D.C

Olsen, S.R., Sommers, L.E., Page, A.L., 1982. Methods of soil analysis. Part 2, (1982): 403-430.

Özbek, A.K., Öztaş, T., 2002. Karasu ovası taban suyu özelliklerinin yersel değişim parametrelerinin belirlenmesi. Su Havzalarında Toprak ve $\mathrm{Su}$ Kaynaklarının Korunması, Geliştirilmesi ve Yönetimi Sempozyumu Bildiri Özetleri, Antakya/Hatay, 2002.

Pagliai, M., Marsili, A., Servadio, P., Vignozzi, N., Pellegrini, S., 2003. Changes in some physical properties of a clay soil in Central Italy following the passage of rubber tracked and wheeled tractors of medium power. Soil and Tillage Research, 73(1): 119-129.

Pierce, F., Larson, W., Dowdy, R. ve Graham, W., 1983. Productivity of soils: Assessing long-term changes due to erosion. Journal of Soil and Water Conservation, 38 (1): 39-44.
Randolph, J. (2004). Environmental land use planning and management. Island Press, Londan 2004.

Rhoades, J., 1982. Cation exchange capacity, Methods of soil analysis. Part 2. Chemical and microbiological properties, p149-157.

Richards, L.A., 1954. Diagnosis and improvement of saline and alkali soils. Soil Science, 78(2): $154 .$.

Riquier, J., Bramao, D.L., Cornet, J.P., 1970. A new system of soil appraisal in terms of actual and potential productivity (first approximation). FAO Soil Resources, Development and Conservation Service. Land and Water Development Division, Rome.

Rogowski, A., Wolf, J., 1994. Incorporating variability into soil map unit delineations. Soil science society of America Journal, 58(1): 163-174.

Smyth, A., Dumanski, J., 1993. FESLM: An international framework for evaluating sustainable land management. Rome:FAO, p.76.

Soil Science Division Staff, 2017. Soil survey manual. United States Department of Agriculture. US Government Printing Office.

Soil Survey Staff, 1999. Soil taxonomy: A basic system of soil classification for making and interpreting soil surveys. US Government Printing Office.

Şeker, C., Işıldar, A., 2000. Tarla trafiğinin toprak profilindeki gözenekliliğe ve sıkışmaya etkisi. Turkish Journal of Agriculture and Forestry, 24(2000): 71-77.

Şenol, S., 1983. Arazi toplulaştırma çalışmalarında kullanılabilir niceliksel yeni bir arazi derecelendirme yönteminin geliştirilmesi üzerine araştırmalar. Doktora Tezi. Çukurova Üniversitesi Fen Bilimleri Enstitüsü, 148s, Adana.

Tekwa, I., Shehu, H., Maunde, S., 2011. Soil nutrient status and productivity potentials of lithosols in Mubi Area, Northeastern Nigeria. Agric Biol J North Am., 2(6): 887-896.

Tunçay, T., 2018. Kurak ekolojik koşullar altında oluşmuş toprakların detaylı toprak etüt haritalama çalışması ve sınıflaması. Akademik Ziraat Dergisi, 8(1), 101-112.

Ulgen, N., Yurtsever, N., 1984. Türkiye gübre ve gübreleme rehberi. Tarım Orman ve Köyişleri Bakanlığı. Topraksu Genel Müdürlüğü, Yayın No 47, Ankara.

Van Wambeke, A.R., 2000. The Newhall simulation model for estimating soil moisture and temperature regimes. Department of Crop and Soil Sciences. Cornell University, Ithaca, NY.

Verheye, W.H., 2009. Land use, land cover and soil sciences-volume IV: Land use management and case studies. EOLSS Publications/UNESCO, Oxford.

Zengin, M., Gezgin, S., 2013. KOP bölgesi tarım topraklarının problemleri ve çözüm yolları. Ulusal KOP Bölgesel Kalkınma Sempozyumu, 14-16 Kasim 2003, Konya. 